\title{
Lo siniestro en el audiovisual: Caracterizaciones sonoras
}

\author{
Adrien Faure Carvallo|adrienfaure@ub.edu \\ Universitat de Barcelona \\ Diego Calderón Garrido|dcalderon@ub.edu \\ Universitat de Barcelona \\ Josep Gustems Carnicer|jgustems@ub.edu \\ Universitat de Barcelona
}

\author{
Palabras clave \\ "Música", "sonido", "emociones negativas", "cine \\ de terror", "cine fantástico" \\ Sumario \\ 1. Introducción. Un acercamiento a lo siniestro \\ en el audiovisual. \\ 2. Metodología., \\ 3. Resultados, \\ 3.1. Altura del sonido. \\ 3.2. Intensidad del sonido. \\ 3.3. Timbre sonoro. \\ 3.4. Melodía. \\ 3.5. Armonía. \\ 3.6. Ritmo. \\ 3.7. Silencio. \\ 4. Conclusiones. \\ 5. Bibliografía. \\ 6. Filmografía
}

\begin{abstract}
Resumen
El sonido, la música e incluso su ausencia, tienen una dilatada tradición social y cultural en la caracterización de cualquier escena audiovisual, tanto en la trama argumental como en los personajes centrales de cada escena. En este sentido, las emociones de los espectadores son reforzadas y manipuladas a gusto del director gracias al sonido. Además, su uso en los audiovisuales ha ido parejo a la aceptación social del mal y la fealdad en sus múltiples facetas en los productos estéticos del siglo XX y XXI y la evolución que estos han tenido. El objetivo de este artículo es hacer un repaso de los principales recursos sonoros y musicales empleados en la caracterización del mal, ya
\end{abstract} sea en forma de conflicto, personaje o sentimiento. Para ello se ha aplicado una metodología descriptiva mediante un análisis sonoro de multitud de ejemplos audiovisuales de las últimas décadas. Los resultados obtenidos permiten distinguir evoluciones estéticas, tendencias y perfiles sonoros de lo siniestro, según el target al que pueda estar destinado el producto audiovisual.

\section{Cómo citar este texto:}

Adrien Faure Carvallo, Diego Calderón Garrido, Josep Gustems Carnicer (2021): Lo siniestro en el audiovisual: Caracterizaciones sonoras en Miguel Hernández Communication Journal, Vol. 12 (1), pp. 203 a 219. Universidad Miguel Hernández, UMH (Elche-Alicante). DOI: https://doi.org/10.21134/mhcj.v12i.942 


\title{
The sinister in the audiovisual: Sound characterizations
}

\author{
Adrien Faure Carvallo|adrienfaure@ub.edu \\ Universitat de Barcelona \\ Diego Calderón Garrido|dcalderon@ub.edu \\ Universitat de Barcelona \\ Josep Gustems Carnicer|jgustems@ub.edu \\ Universitat de Barcelona
}

Keywords

"Música”, "sonido", "emociones negativas", "cine de terror", "cine fantástico"

Summary

1. Introduction. An approach to the sinister in the audiovisual.

2. Methodology

3. Results.

3.1. Sound height.

3.2. Intensity of the sound.

3.3. Timbre of the sound.

3.4. Melody.

3.5. Harmony.

3.6. Rhythm.

3.7. Silence.

4. Conclusions.

5. Bibliography.

6. Filmography

\section{Abstract}

Sound, music and even its absence have a long social and cultural tradition in the characterization of any audiovisual scene, both in the plot and in the central characters of each scene. In this sense, the emotions of the spectators are reinforced and manipulated as the director likes thanks to the sound. In addition, its use in audiovisuals has gone hand in hand with the social acceptance of evil and ugliness in its many facets in the aesthetic products of the 20th and 21st centuries and the evolution that these have had. The aim of this article is to review the main sound and musical resources used to character-

ize evil, whether in the form of conflict, character or feeling. A descriptive method is applied through a sound analysis of a multitude of audiovisual examples from the last decades. The results obtained allow us to distinguish aesthetic developments, trends and sound profiles from the sinister, according to the target for which the audiovisual product may be intended.

\section{How to cite this text:}

Adrien Faure Carvallo, Diego Calderón Garrido, Josep Gustems Carnicer (2021): Lo siniestro en el audiovisual: Caracterizaciones sonoras en Miguel Hernández Communication Journal, Vol. 12 (1), pp. 203 a 219. Universidad Miguel Hernández, UMH (Elche-Alicante). DOI: https://doi.org/10.21134/mhcj.v12i.942 


\section{Introducción}

La historia del cine y del audiovisual está íntimamente ligada al uso de la música y el sonido como elemento fundamental de su concepción artística. Desde la aparición y expansión del cine sonoro a finales de la década de 1920, el sonido y la música han ocupado un papel relevante en la dimensión expresiva del audiovisual, ya sea en su faceta emocional, informativa o contextualizadora. La música, las voces y diálogos, y los efectos sonoros, por referirnos a los tres grandes bloques que aquí se examinarán, influyen secretamente en la experiencia del público que asiste a un evento audiovisual, ya sea en un cine, ante una televisión o una pantalla de un dispositivo móvil (Nieto, 2003).

Si nos atenemos a los tradicionales géneros cinematográficos, encontramos el llamado cine fantástico, con sus múltiples aspectos vinculados al terror. En este contexto, estamos ante productos audiovisuales que enfatizan y reiteran las emociones negativas (especialmente el miedo, aunque este pueda ir acompañado de ira, tristeza, pasividad, aburrimiento, sorpresa, etc.) (Hutchings, 2004; Marimón, 2013). Asimismo encontramos apariciones puntuales de emociones negativas en otros géneros como la tragicomedia, el cine histórico épico (guerras, conquistas, batallas...) e incluso la animación o los videojuegos (Gómez, 2014; Sedeño, 2010).

La relación de la música con lo maligno no es nueva ni reciente, se remonta a la edad Media. Se fundamenta en la capacidad para crear desarmonía y su poder para alentar las bajas pasiones a través de los sentidos (Perpiñá, 2013). Instrumentos como la flauta o la cítara fueron alejados de los cultos cristianos por asociarse con el diablo, la danza o la lujuria, alejándose del carácter humano de la voz (Polo, 2016). Hacia el siglo XII aparecen las llamadas cabalgatas de los pecados, representaciones iconográficas que personifican las faltas capitales mediante animales alegóricos (Sebastián, 1988). Estas cabalgatas pueden aparecer acompañadas de instrumentos, interpretadas por personajes relacionados con la juglaría, o por animales músicos, como ocurre en uno de los capiteles de la Basílica de Saint-Julien à Brioude en el Alto Loira (s. XII) (ver figura 1). El tipo iconográfico del animal músico es, de nuevo, una asociación de la música con el pecado.

Fig. 1. Animal músico en un capitel de Saint-Julien à Brioude. Fuente: Perpiñá, 2013.

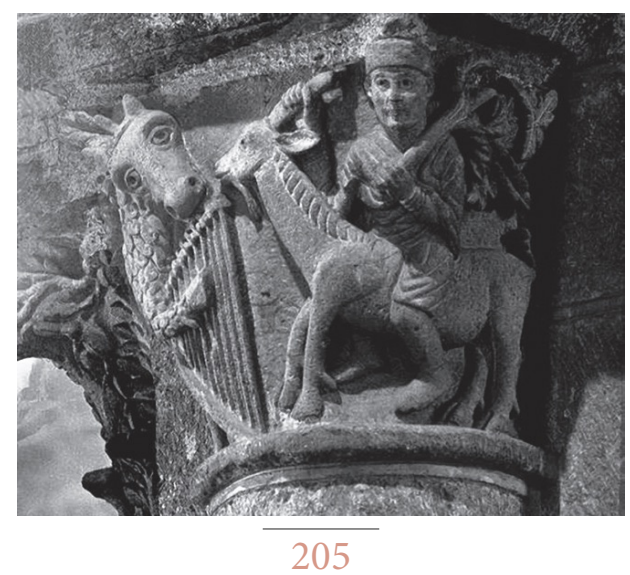


En la literatura rondallística y el mundo de los cuentos populares, la presencia de lo maligno acompaña a los protagonistas, ya sean héroes, niños o seres corrientes. Trabajos como el de Bettelheim (2012) analizan en profundidad el valor formativo de los conflictos y su localización en forma de etapas y dificultades a superar en el tránsito del mundo infantil al de los adultos. El mundo de los audiovisuales, a su vez, incluye múltiples ejemplos de este tipo de situaciones.

La presencia ocasional de emociones negativas en un audiovisual es inherente a la condición humana y a la evolución y crecimiento personal de los personajes de la historia que reflejan (Duran, 2009), aunque debamos respetar cierta proporcionalidad en su uso respecto a las emociones positivas o neutras. En este sentido es imprescindible tener en cuenta los trabajos de Fridja (1988) y su Ley de la Asimetría Hedónica, señalando que las emociones negativas tienden a perdurar en el espectador unas cinco veces más que las positivas. Este hecho será fundamental en el montaje de un producto audiovisual, y deberá ir de la mano de las intenciones que persiga su autor. También será un serio condicionante, como veremos en las páginas que siguen, de la elección cuidadosa del audio que contendrá el audiovisual.

En la tradición primordial y el simbolismo, frente a lo infernal, lo malvado, lo siniestro, caben dos grandes posicionamientos epistemológicos (Cirlot, 2004), que condicionarán fundamentalmente la trama expresiva: el mal como fuerza opuesta al bien, de igual intensidad pero signo contrario; y el mal como desviación momentánea intencionada o ausencia del bien. Estos dos posicionamientos nos enfrentarán a dos tipos de seres malignos: los que comparten la fuerza y dimensión de los seres buenos pero de signo contrario (véase: demonios, diablos, brujas, endemoniados, monstruos, invasores, vampiros, aparecidos, muertos malvados... que quiebran el principio de realidad, siguiendo el modelo de Satán), y los que se camuflan entre el resto de humanos pues comparten la mayoría de sus características, pero que pueden realizar actos malvados de forma selectiva y esporádica (véase psicópatas, guerreros, verdugos, genios, muñecos autómatas, en definitiva, encarnaciones de Lucifer), entremezclando lo familiar y lo extraño, la realidad y la ficción.

Estos segundos, luciferinos, viven en ocasiones una dualidad, una lucha interna entre el bien y el mal, debatiéndose interiormente para establecer un patrón en su vida que permita clasificarlos en un bando u otro, aunque normalmente no lo consigan. Su testimonio señala que la maldad es una condición altamente humana, que se encuentra en la cotidianidad de la vida de todos y cada una de las personas (Jiménez, 2010). La perversidad no está presente únicamente en animales de naturaleza salvaje o seres fantásticos y mitológicos, sino que acontece en las personas normales y corrientes, hombres y mujeres que no necesitan de poderosos y malévolos atributos mágicos para pervertir a toda la comunidad que se antepone a sus planes. No es necesario que estas figuras perversas posean atributos para cambiar de apariencia o poderes sobrenaturales a través de los cuales sembrar el pánico y depravar a la humanidad, sino que la malignidad puede residir en la propia humanidad. Un buen ejemplo de ello sería la transformación del leitmotiv de Anakin Skywalker (más tarde, Darth Vader), un personaje de la saga StarWars que empieza siendo caracterizado como bueno y poco a poco se irá transformando hacia lo maligno, evolución que recogerá y expresará magníficamente en términos musicales (melodía y armonía de su leitmotiv), principalmente el compositor de la saga. No solo el cine crítico y realista contemporáneo 
contempla escenas en este sentido, sino que incluso un clásico infantil como Disney, dibuja así algunos de los malos de los clásicos de animación de Disney (Monleón, 2018).

Ambos prototipos, aunque coincidentes en buena parte (su aspecto siniestro y malévolo), utilizan habitualmente dos expresiones dramáticas bien distintas que les caracterizan, en cuanto a que potencien o no su parecido con el resto de humanos y situaciones convencionales. Los sonidos que los acompañan en los audiovisuales configuran también esta dualidad.

El objetivo de este artículo es describir los principales recursos sonoros empleados en la expresión de lo siniestro en los audiovisuales, y conocer algunas de las razones que los han hecho tan singularmente eficaces.

\section{Metodología}

Este trabajo es de tipo descriptivo y se fundamenta en el análisis documental para presentar una exposición detallada de los contenidos presentes en la caracterización sonora de lo siniestro en los audiovisuales. Para ello se diseñó un instrumento que permitiera la recogida de datos y su posterior estructuración y presentación (Bisquerra, 2004). El instrumento consistía en una ficha de análisis que incluyese las variables en estudio así como la procedencia del documento. Para ello se delimitaron las variables en estudio a partir de los ejes conceptuales presentes en los tratados de música y de teoría musical más divulgados. A partir del listado inicial de variables, que incluía las cualidades del sonido y los elementos de la música, se cotejaron con diversos jueces -profesores doctores de Historia del Arte de la Universidad de Barcelona- para su validación y mejora, resultando finalmente los que se presentan en el apartado de resultados: altura, intensidad, timbre, melodía, armonía y ritmo.

Dichas variables se refieren a las cualidades del sonido y a los elementos de la música, y han sido utilizadas en numerosas investigaciones de carácter multimodal (Calderón, Gustems y Martín, 2017; Zamacois, 1978). Asimismo se incluyó el silencio como elemento expresivo, tal y como afirman muchos investigadores de los audiovisuales (Gustems, 2012). Se excluyeron del estudio aquellos conceptos que podían llevar a confusión terminológica (como el caso de estilo y género, por ejemplo) o bien aquellos que quedaban en un nivel abstracto (como textura). A partir de aquí se aplicó dicha clasificación a una búsqueda bibliográfica amplia on line, en repositorios habituales para Artes y Humanidades (como ERIC, o Google adadémico) de carácter multidisciplinar, de los últimos 20 años, con los términos "sonido" "siniestro" y próximos, resultando un total de 215 entradas que se fueron descartando por ser inoperativas o inconsistentes, hasta resultar 18, sobre las que se ha fundamentado los resultados que se presentan a continuación en forma relatada.

\section{Resultados}

La necesidad de enfatizar y conducir al público a la comprensión de las intenciones y moral de los personajes de una obra musical o escénica se remontan a la Antigüedad 
Griega. De esta época remontan las primeras sistematizaciones en la atribución de efectos emocionales a la música. Desde entonces, todos los estilos artísticos han profundizado en dicha capacidad expresiva y comunicativa, con mayor o menor énfasis en determinadas emociones o situaciones que han impregnado la música e incluso la terminología musical (Calderón, Gustems, Martín, Fuentes y Portela, 2020).

Para describir en detalle los recursos sonoros más importantes empleados en este sentido, seguiremos las cualidades del sonido y los elementos de la música que mayor efecto puedan ejercer sobre la caracterización de lo siniestro en los audiovisuales. Cabe destacar que las emociones negativas asociadas a lo siniestro (miedo, ira, tristeza) pueden ser expresadas de forma habitual por la música y el sonido, por lo que queda muy bien justificado su uso intencionado en los audiovisuales y el mundo escénico (Juslin y Laukka, 2004).

\subsection{Altura del sonido}

La altura del sonido es uno de los recursos expresivos utilizados en la definición sonora del grado de irrealidad y transgresión de límites en las situaciones y personajes. Normalmente las voces de los personajes siniestros se sitúan en los extremos agudo y grave de lo humanamente corriente, es decir, fuera del ámbito habitual. Así es habitual escuchar a un bajo profundo doblar un monstruo en sus diálogos o rugidos, sobre todo debido al supuesto gran tamaño de su cuerpo, a quien correspondería una voz grave, igual que sucede con los instrumentos graves de gran tamaño. La sensación de poder que se otorga a las voces y sonidos graves guarda relación con el efecto protector o aterrador de los animales o seres de mayor tamaño, que tienen más posibilidades de vencernos en una lucha. Por ese motivo son preferidas estas voces graves para acompañar personajes con poder físico o terrenal (reyes, jueces, médicos, sabios...), que suelen expresarse con lentitud y pausas (Collins y Missing, 2003).

En este sentido, la mayoría de personajes malévolos son del género masculino, con voces más graves que las de las mujeres, sería el caso del 75\% en los clásicos de Disney (Monleón, 2018). Muchos son los ejemplos audiovisuales que ilustran este detalle acústico, entre ellos, queremos destacar la voz de la planta (cada vez más grave cuanto más crece) del film La pequeña tienda de los horrores (Roger Corman, 1960). Lo grave denota poder, tamaño y determinación, por eso algunas mujeres, cuando envejecen y sus voces se hacen algo más graves, aumentan en asertividad, dominancia y libertad (Ramadan, 2015).

En el caso de voces agudas, el uso de voces infantiles es bastante frecuente por su atribución a la inocencia, al victimismo y a la indefensión frente al maligno, contrastando la luz frente a la oscuridad o la sombra (Sapró, 2012). A partir de aquí se establecen una serie de clichés sonoros que construyen una relación anempática con el contenido argumental y visual del audiovisual, pero que consiguen provocar la sensación de miedo que se persigue desde un principio; por ejemplo, el uso de cajas de música, juguetes, canciones infantiles, etc. -véase A Nightmare on Elm Street (Wes Craven, 1984)-. Igualmente, las voces hiperagudas dan sensación de incredulidad, de irrealidad, de extrahumanos; ejemplos de ello serían la soprano ligera/Reina de la noche, del Singspiel Der Zauberflute, de W.A. Mozart, o los pitidos 
vocales de Wall-E (Pixar, 2008).

\subsection{Intensidad del sonido}

La intensidad del sonido juega un importante papel en nuestra respuesta de activación nerviosa, lo que los neurocientíficos denominan arousal. Los sonidos, músicas y voces fuertes nos conmocionan, aturden y asustan. Es lógico pensar que cuanto mayor sea el poder de un ser siniestro, mayor será la intensidad de los sonidos que pueda emitir o provocar. Esto nos invoca a emociones con alto grado de arousal, como pueden ser el entusiasmo (en positivo) o la ira (en negativo), utilizadas en contextos de guerra, lucha o venganza, en los géneros cinematográficos que les son propios (Iriondo, 2008).

En este sentido, algunas situaciones inquietantes en los audiovisuales se provocan mediante cambios bruscos de intensidad, provocando una fuerte sorpresa, así como mediante voces susurrantes, que se sitúan en una gran proximidad con el personaje y que obligan a un acercamiento a seres malvados que nos causa miedo por no poder distanciarnos. Tal sería el habla de un encantador, un embaucador, una bruja, alguien que nos engaña y quiere hacernos daño, alguien en quien confiar porque su intensidad sonora no despierta precaución sino compasión y cercanía, como la palabra Rosebud susurrada por el moribundo Orson Welles, en su papel de Charles Foster Kane, durante los primeros minutos de Citizen Kane (Orson Welles, 1941).

\subsection{Timbre sonoro}

El timbre sonoro ha tomado gran relevancia expresiva en la medida en que ha sido posible la manipulación de sus componentes mediante técnicas mecánicas, eléctricas y electrónicas (Sonnenschein, 2001) a partir de la década de 1930. El cine ha aprovechado estos recursos para forzar los personajes y buscar el máximo acuerdo entre lo que se ve y lo que se escucha. Esto sería claramente observable en voces imaginarias, tales como las de seres extraterrestres, monstruos, en que ningún sonido real sería tomado para ser asignado a un ser ficticio. A modo de ejemplo, nos remitiremos al rugido de King Kong (Merian C. Cooper y Ernest B. Schoedsack, 1933), con el cual, para muchos, Murray Spivack, al transformar el rugido de un león en el grito de un gorila gigante, dio el pistoletazo de salida a lo que hoy en día se conoce como "diseño de sonido" (Murch, 2000).

En otro nivel creativo tendríamos voces reales pero modificadas, para enfatizar alguna de las características del personaje que acompañan: este sería el caso de brujas, sirenas y un largo etc. de ejemplos cinematográficos donde el audio de un personaje es retocado electrónicamente (a modo del Photoshopen las fotografías). La alteración de las características naturales de la voz llevándolas a límites de desagrado en su escucha es uno de los recursos más habituales (por ejemplo, la voz modificada de Linda Blair en El Exorcista, 1973).

De este modo, el procesado del sonido nos permite modular el impacto de todo aquello que suena, durante la fase de posproducción de audio. Así, el contenido argumental y visual de una obra será reforzado o atenuado mediante la dimensión sonora del audiovisual. Cabe destacar que cuando nos referimos a la música o al sonido, rara vez utilizamos palabras pertenecientes al lenguaje musical, sino que la mayoría de las veces usamos metáforas 
fruto de las asociaciones establecidas históricamente mediante su uso en las producciones audiovisuales. Así pues, regresando a lo maligno, a menudo usaremos adjetivos como estridente, saturado, frío u oscuro, cuando nos refiramos a una configuración u otra de la ecualización del sonido de una producción.

Por lo tanto, en una escena escalofriante de una película de terror, el ingeniero de sonido podrá, por ejemplo, saturar los sonidos, mediante procesos de manipulación sonora, para reforzar la sensación de miedo del espectador. Será la combinación de aquello que suena con el modo en que ha sido procesado, lo que potenciará el significado del relato que se nos esté contando en el guion.

Entre los recursos de manipulación sonora más habituales encontramos el cambio de pitch -que nos permite modificar la altura de los sonidos, remitiéndonos al anterior ejemplo de ElExorcista-, la distorsión o saturación, la ecualización, la reverberación y un largo etcétera. A continuación, trataremos el ejemplo de la compresión; recurso muy utilizado para la regulación del miedo en los audiovisuales y, a menudo, menos conocido que el resto.

En el punto anterior hacíamos referencia al papel del contraste de intensidades para crear efectos potentes sobre la percepción de los espectadores. En este caso, la compresión es la herramienta que permitirá controlar el rango dinámico en una escena determinada. En 1993, se estrenó Jurassic Park (Steven Spielberg), película merecedora de los Oscar al mejor sonido y a la mejor edición de sonido, entre otros muchos. Aunque la creatividad del diseño sonoro de los rugidos de los dinosaurios se llevó buena parte de este mérito, también hay que destacar el trabajo de posproducción sonora. Destacaremos la escena en la que unos niños quedan atrapados en una cocina mientras les acecha un velocirraptor. La sensación de claustrofobia se ve potenciada, en este caso, mediante la compresión; es decir, la reducción del rango dinámico entre los sonidos de mayor y menor intensidad. De este modo, somos capaces, como espectadores, de oír los susurros e, incluso, la respiración de los jóvenes acorralados mientras el dinosaurio se acerca a ellos golpeando sus garras inquietantemente contra el suelo.

Otro ejemplo de posproducción al servicio de las emociones más inquietantes lo encontramos en Blade Runner 2049 (Denis Villeneuve, 2017). En esta película, vemos un futuro distópico donde la ciudad de Las Vegas ha sido reducida a un desierto carente de vida y que encarna la idea de lo desconocido, lo peligroso y lo amenazante. En la llegada del protagonista a este inhóspito lugar, el sonido juega un papel crucial creando un fuerte contraste, que alterna silencio y sintetizadores atronadores, con un tratamiento sonoro muy específico: el refuerzo de las frecuencias graves en la ecualización, para transmitir amenaza y malestar, junto con una reverberación grandiosa y de larga duración, para sugerir la inmensidad del lugar y el misterio que esconde en su interior.

Por otro lado, en la descripción de lo siniestro aparece con mucha frecuencia los efectos de sonido -a modo de ruido-, aprovechando su capacidad de rudeza y timbre rasposo y molesto que le caracteriza. Un ejemplo paradigmático podrían ser los sonidos de moscas y otros insectos asociados a la podredumbre de los cadáveres en alguna escena de El Exorcista (William Friedkin, 1973), o lo que usualmente se denomina sonido interno (latidos, 
respiraciones, etc.), como hemos descrito en el ejemplo de Jurassic Park.

Respecto al uso de instrumentos musicales en situaciones siniestras, cabe destacar algunos antecedentes históricos en la música, como la atribución al infierno del sonido del sacabuche (antepasado del trombón de varas) en el Orfeo, de C. Monteverdi (1607), el uso excesivo del violín -siguiendo la leyenda de Paganini que podemos percibir en Si yo fuera rico, y las referencias al órgano ad oppositum, por oposición a su habitual uso religioso (El Anticristo, 1974, Alberto de Martino y Ennio Morricone). Respecto a timbres más populares, también es notable el uso de campanas -como símbolo de la tradición católica, especialmente en sus toques fúnebres- y su sustitución ocasional por las grandes carracas y tinieblas instaladas en las catedrales para algunos momentos trágicos del periodo pascual (Crivillé, 1983).

El conjunto orquestal también ha sido elegido como estandarte de la grandeza o supremacía más allá de la moral, véase el caso de la predilección del III Reich por obras de Beethoven, Bruckner y Wagner (VV AA, 2007). De igual modo, algunas escenas infernales utilizan el canto gregoriano y los coros (La profecía, Richard Donner, 1976), en un uso pretendidamente indebido de la tradición católica (al estilo de Lucifer).

\subsection{Melodía}

En el ámbito melódico, uno de los preferidos por la música occidental de todos los tiempos, podemos referirnos a varios recursos ampliamente utilizados en este contexto: el leitmotiv, el diabolus in música, la evitación melódica, el microtonalismo y el atonalismo.

Denominamos leitmotiv a un motivo melódico característico que permite identificar un personaje o una situación mediante su identificación con el mismo, creada por repetición y asociación sensorial a lo largo de una obra (Wingstedt, Brändström y Berg, 2010). Son famosos los leitmotiv de las óperas de R. Wagner, que nos recuerdan personajes que no están presentes en la escena mediante pequeñas melodías que los caracterizan. En un plano más actual también los encontramos en el cine, de la mano de Indiana Jones, James Bond o del célebre Tiburón.

Respecto al llamado diabolus in música, se refiere a la utilización deliberada y destacable del intervalo melódico de tritono ( $4^{a}$ de tres tonos) (Deutsch, North y Ray, 1990). En la edad media, cuando culminó su asignación estético-moral negativa, tal intervalo no solía aparecer en las melodías gregorianas y se evitaba debido al sistema hexacordal propuesto por Guido d'Arezzo en su Musica enchiriadis, que nunca llegó a prohibirlo (Hammerstein, 1974). En el s. XIII se le tildó de discordantia perfecta, con su consiguiente atribución al diablo por su carácter imperfecto. Schönberg (1974), en su Tratado de Armonía, justifica nuestra dificultad en asimilarlo en la melodía por su difícil consonancia mediante su ratio acústica de 32/45.

En los siglos posteriores, su uso estuvo vinculado sobre todo con el acorde de $7^{\mathrm{a}}$ de dominante, aunque en ocasiones se destacó en los timbales (Beethoven, Fidelio, act. 2) o en el famoso acorde Tristán (R. Wagner: Tristan und Isolde, $1 \mathrm{r}$ acto), cuyo desarrollo contribuyó paulatinamente a la suspensión de la tonalidad. Tanto la música electrónica como el Heary Metal, tachado de satánico en ocasiones, usan dicha combinación para algunos de sus riff. En el mundo audiovisual sorprende su uso en animación para destacar escenas o situaciones 
conflictivas (Pepa Pig, princesa Holly, Patrulla canina, Bob Esponja, Caillou...). El tritono consigue ser, un milenio más tarde, motivo de excitación y nerviosismo a quien lo escucha (Costa, Fine y Ricci, 2004).

Con la denominación de evitación melódica, nos referimos al uso del canto hablado, recitado o gritado, en vez del habitual canto melódico. Este es el caso de algunos géneros musicales actuales como el Rap-hip hop, el punk o el metal, que claramente evocan emociones de menor valencia que otros más mayoritarios, como el góspel, pop, reggae o el rock (Dodds y Danforth, 2010).

Otros de los recursos melódicos empleados en la música clásica contemporánea, utilizados en obras con un claro contenido perturbador, serían el uso del microtonalismo, del glissando y de la atonalidad, de concepción creativa cercana a la música aleatoria y con un claro contenido errático y desorientador. Un ejemplo lo tenemos en Atmosphères (Ligeti, 1961) en el film 2001, Odisea en el espacio (Kubrick, 1968) donde la música se desarrolla a través de masas de sonido sin una afinación percibida concreta.

En general, la música de lo siniestro en los audiovisuales es sorprendente, desconocida, no nos resulta familiar, por lo que no genera emociones positivas (Sloboda, 1999).

\subsection{Armonía}

La armonía musical se refiere a la concurrencia simultánea de varios sonidos y las sensaciones producidas a partir de sus distintas alturas, sin tener en cuenta otros parámetros como la intensidad relativa de sus sonidos o sus timbres. En este sentido hablamos de consonancias, cuando los sonidos conjuntados producen una sensación fácil, bella o neutra, mientras que la disonancia se referiría a la dificultad en aceptar determinadas combinaciones y la necesidad provocada de resolver dicho acorde en otro más agradable al oído (Trainor, Tsang y Cheung, 2002).

De forma general, la música que evoca emociones positivas trabaja con acordes consonantes, sobre todo los calificados como modo mayor (Juslin y Laukka, 2004). Los de modo menor son muy aceptados pero con un componente de valencia menos positivo (como la tristeza) (Juslin y Laukka, 2004). A partir de aquí, la complejidad sonora de las disonancias va en aumento, hasta llegar a los clusters, o racimos de notas muy juntas que suelen provocar una sensación de desasosiego. Si las disonancias se realizan con sonidos graves, estos aún provocan peores sensaciones acústicas que si son agudos; por este motivo algunas músicas las emplean para referirse a los infiernos (como los Gurrelieder de Arnold Schönberg, 1912; o las referencias al infierno en el Orfeo, de Claudio Monteverdi, 1607). En escenas audiovisuales debemos recordar los créditos iniciales de Psicosis y partes centrales bélicas de El señor de los anillos.

\subsection{Ritmo}

El tempo y el ritmo son componentes básicos en la evocación emocional, así lo señala la gran tradición musical universal. Las referencias bélicas provocadas por redobles y ritmos 
de batalla y de marcha militar indican la intencionalidad en crear escenarios de miedo, confusión, ruido y fuerza colectiva. Emociones como la ira se exacerban con ritmos rápidos, mientras que la lentitud puede provocar angustia y desesperación en escenas de pánico, tortura o dolor. Según Marimón (2013), la lentitud de la espera se transforma en extrema rapidez en el instante de la agresión en filmes de terror. En ningún otro género se presenta un contraste rítmico más acusado, la poética lentitud de la creación del miedo y la terrible velocidad de la violencia. Este accelerando inesperado excita y eleva el arousal del espectador.

Otro recurso rítmico asociado con el miedo es el uso de interrupciones del fluir natural, por ejemplo, el tremolo, el vibrato rápido de algunos cantantes (como Anthony and the Johnsons) o el ritmo espasmódico e interrumpido a trompicones propio de la expresión de las contracciones del miedo (podemos escucharlo en Mussorgsky, Una noche en el monte pelado).

Respecto al compás y a las subdivisiones naturales de los tiempos, la historia de la música nos recuerda la asociación del ternario con la perfección, a lo largo de la Edad Media (especialmente en el estilo Ars Antiqua, de los ss. X, XI y XII). Esta asociación del ritmo ternario con la Sma. Trinidad está avalada por Juan de Muris, S. Agustín y Boecio y mantendrá su influencia hasta el Ars Nova y el Renacimiento, cuando los ritmos binarios serán perfectamente acogidos en todo tipo de música (Jay Grout, 1985).

\subsection{Ritmo}

Finalmente, no podemos obviar al silencio como recurso expresivo en los audiovisuales. Según Chion (1993), el silencio es una variación del sonido, con características totalmente opuestas a este, pero con su misma naturaleza -es decir, se desarrolla en el tiempo y contiene variaciones-. Por lo tanto, tiene las mismas capacidades simbólicas que el sonido, pudiendo ejercer sus mismas funciones dramáticas y estéticas (Rodríguez, 1998). Pero como hemos comentado, sus características son distintas. En cuanto a su capacidad para caracterizar el mal, destacaremos las siguientes peculiaridades que definen el silencio.

En primer lugar, el silencio es indefinido -podríamos decir que no hay dos silencios iguales- y goza de ambigüedad. Es decir, el mismo no-sonido puede tener muchas causas. Esto resulta de gran utilidad para confundir a los espectadores y generar una sensación de angustia, miedo o pérdida de control. Por ejemplo, en la película Érase una Vez en el Oeste (Sergio Leone, 1968), nos encontramos con una escena en la que una familia se haya apaciblemente en su rancho cuando, de pronto, un disparo marca el inicio de una secuencia de silencio. Durante el transcurso de ese silencio, el espectador no sabe si el disparo provenía de un cazador o de una amenaza y, precisamente durante la espera silenciosa, es cuando se genera la sensación de incerteza y desasosiego. Este mismo ejemplo sirve también para ilustrar la otra característica esencial del silencio: el contraste. El silencio no tiene por qué ser la ausencia de sonido, sino que trabaja con relación a los sonidos anteriores y posteriores a él. De este modo, el silencio puede ser sonoro, pero se percibe como tal al estar marcado por un contraste (Rodríguez, 1998), recurso ampliamente extendido en las producciones de terror que buscan sorprender o sobresaltar al espectador. 


\section{Conclusiones}

Tal como demostraron Juslin y Laukka (2004), la música expresa y evoca de forma magistral la alegría (entusiasmo), la felicidad (calma) y la tristeza, por eso, la necesidad de recurrir también al tratamiento sonoro profuso de las voces y los ruidos en la evocación de las emociones propias de lo siniestro: el miedo y la ira. El audio de un film o de un audiovisual está perfectamente capacitado para expresar todo tipo de situaciones siniestras y evocar las emociones correspondientes (Lerner, 2010). Además, en esta tarea, las artes visuales, escénicas y la literatura ofrecen muchos recursos que, en el contexto de los audiovisuales, representarán un complemento eficaz al sonido.

$\mathrm{El}$ audio en los audiovisuales representa un recurso multimodal con grandes posibilidades en la caracterización de lo siniestro. Tanto las voces y su tratamiento, como los ruidos y sonidos ambientales y la música conllevan elementos que evocan las emociones negativas vinculadas con el miedo y son un soporte único en su expresión. Además, implican la inclusión y el desarrollo de dinámicas novedosas y creativas ante el sonido, resultando un espacio ideal para los creadores e investigadores musicales de vanguardia. De hecho, buena parte de los compositores actuales están centrados en la creación sonora para audiovisuales.

Para Sapró (2012), lo siniestro representaría el encuentro de lo misterioso, lo tremendo y lo fascinante. Tres elementos caracterizados sonoramente por la sorpresa y novedad, la grandiosidad de su expresión negativa y sorprendentemente, la fascinación que ejerce en el público. Ya estemos ante la expresión de la maldad en toda su profusión, como en su expresión ocasional, los recursos sonoros aquí descritos garantizan su comprensión y enfatizan su sentido rotundo -al estilo demoníaco satánico monstruoso- o al estilo discreto luciferino.

Además, el arte -y los audiovisuales como arte privilegiado del presente y del futuro- puede ejercer una función catártica, un entrenamiento emocional vicario (Vigotsky, 1972) ante situaciones adversas que podemos anticipar y controlar hasta un cierto punto mediante las experiencias artísticas, en este caso, audiovisuales. Conocer nuestra respuesta a lo siniestro, a lo perturbador y a la vez excitante, puede ayudar a conocernos mejor y evitar situaciones de peligro y amenaza. Los programas de entrenamiento mediante la realidad virtual aprovechan este potencial sonoro para incluirlo en sus propuestas de programar o desprogramar individuos en situaciones muy adversas y aprender a superarlas mucho mejor.

No queremos terminar nuestra aproximación sonora a lo siniestro sin referirnos a la magistral apreciación que Joan Marimón (2013: 113), profesor de la prestigiosa ESCAC, nos plantea ante el visionado en un cine de una película de terror, cuando dice:

Pero lo relevante es la existencia misma de esa descarga de hilaridad, que viene a significar algo así como: "¡Ah, cómo me he creído el miedo, qué bien lo he pasado!". Obviamente, si el horror fuera de verdad no habría carcajada, lo que atrae es la convincente ceremonia de simulación. Pocas cosas sacuden más nuestro termómetro emotivo y por tanto gustan más a un buen número de espectadores que pasarlo mal de mentira. 


\section{Uso de imágenes}

Las imágenes utilizadas como figuras en este artículo son elementos centrales del análisis, realizado únicamente con fines científicos en el ámbito académico.

\section{Bibliografía}

Bettelheim, B. (2012). Psicoanálisis de los cuentos de hadas. Barcelona: Planeta

Bisquerra, R. (2004). Metodología de la Investigación Educativa. Madrid: La Muralla.

Cirlot, J. E. (2004). Diccionario de símbolos. Madrid: Siruela.

Calderón, D., Gustems, J. y Martin, C. (2017). Multimodalidad, emoción y publicidad. Un estudio empírico sobre Youtube. Icono 14, 15 (2), España, junio, pp. 25-48.

Calderón, D., Gustems, J., Martín, C., Fuentes, C. y Portela, A. (2020). Emociones en la experiencia artística: claves para el desarrollo educativo y social. Artseduca 25, España, enero, pp. 85-101.

Chion, M. (1993). La Audiovisión. Introducción a un análisis conjunto de la imagen y el sonido. Barcelona: Paidós.

Collins, S. A. y Missing, C. (2003) Vocal and visual attractiveness are related in women. Animal Behaviour 65, Estado Unidos, marzo, pp. 997-1004.

Costa, M., Fine, Ph. y Ricci, P.E. (2004). Interval Distributions, Mode and Tonal Strength of Melodies as Predictors of Perceived Emotion. Music Perception 22 (1), Canadá, febrero, pp. 1-14.

Crivillé, J. (1983). Historia de la Música Española. Vol. 7. El Folklore musical. Madrid: Alianza Editorial.

Deutsch, D., North, T. y Ray, L. (1990). 'The Tritone Paradox'. Music Perception 8, Canadá, marzo, pp. 371-384.

Dodds, P. S. y Danforth, C. M. (2010). Measuring the Happiness of large-Scale Written Expression: Songs, Blogs, and Presidents. Journal of Happiness Studies 11, Suíza, mayo, pp. 441-456.

Duran, J. (2009). Narrativa audiovisual $i$ cinema d'animació per ordinador. Barcelona: Universitat de Barcelona. Tesis doctoral. Recuperado de http://www.tdx.cat/bitstream/ handle/10803/1270/03.JDC_3de5.pdf? sequence $=3$

Fridja, N. H. (1988). The Laws of Emotion. American Psychologist 43 (5), Estados Unidos, octubre, pp. 349-358.

Gómez, M. (2014). La música en los videojuegos. En J. Gustems (ed.), Música y Audición en los Géneros Audiovisuales (pp. 67-78). Barcelona: Publicacions i Edicions de la Universitat de 
Barcelona.

Gustems, J. (2012). Análisis de las cualidades del sonido en los audiovisuales. En J. Gustems (coord.), Música y Sonido en los Audiovisuales (pp. 67-92). Barcelona: Publicacions i Edicions de la Universitat de Barcelona.

Hammerstein, R. (1974). Diabolus in Musica. Studien zur Ikonographie der Musik im Mittelalter. Berna: Francke Verlag.

Hutchings, P. (2004). The horror film. Harlow: Pearson.

Iriondo I. (2008). Producción de un corpus oral y modelado prosódico para la síntesis del habla expresiva. (Tesis inédita de doctorado). Universitat Ramon Llull, Barcelona.

Jay Grout, D. (1985). Historia de la música Occidental, vol. 1: Madrid: Alianza Música.

Jiménez, Z. (2010). La construcción del villano como personaje cinematográfico. FRAME 6, España, marzo, pp. 285-311.

Juslin, P.N. y Laukka, P. (2004). Expression, Perception, and Induction of Musical Emotions: a Review and a Questionaire Study of Everyday Listening. Journal of New Music Research 33 (3), Estados Unidos, septiembre, pp. 217-238.

King-Lengzmeier, A. H. (2001). Hildegard of Bingen. An integrated vision. Minnesota: Collegeville Liturgical Press.

Lerner, N. (ed). (2010). Music in the Horror Film Listening to Fear. Nueva York: Routletge.

Marimón, J. (2013). El malestar del bienestar. En J. Gustems (ed.), Arte y Bienestar (pp. 102113). Barcelona: Publicacions i Edicions de la Universitat de Barcelona

Monleón, V. (2018). "El malo de la película" Estudio de las principales figuras malvadas en la colección cinematográfica clásicos Disney (1937-2016). EARI, Educación Artística, Revista de Investigación 9, Valencia, abril, pp. 131-148.

Murch, W. (2000). Stretching sound to help the mind see. New York Times, 1. Recuperado de: $\quad$ http://markmangini.com/Mark_Mangini/Reading_Room_files/Stretching\%20 Sound $\% 20$ to $\% 20$ Help $\% 20$ the $\% 20$ Mind $\% 20$ See $\% 20$ by $\% 20$ Walter $\% 20$ Murch $\% 20$ copy. pdf

Nieto, J. (2003). Música para la imagen: la influencia secreta. Madrid: Iberautor.

Perpiñá, C. (2013). La música del diablo y el diablo en la música. En A. Martínez, I. Osuna y V. Infantes (Eds.), Palabras, símbolos, emblemas (pp. 441-451). Madrid: Turpin Editores.

Polo, M. (2016). La música instrumental y la música vocal en Hieronymus Bosch. Matèria d'Art 10-11, Barcelona, marzo, pp. 149-168.

Salimpoor, V.N., Benovoy, M., Longo, G., Cooperstock, J.R. y Zatorre, R.J. (2009). The Rewarding Aspects of Music Listening Are Related to Degree of Emotional Arousal. Plos 
One 4 (10), Estados Unidos, octubre, pp. e7487.

Ramadan, N. (2015). Aging With Disney and the Gendering of Evil. Journal of Literature and Art Studies 5 (2), Reino Unido, mayo, pp. 114-127.

Rodríguez, M. A. (1998). La dimensión sonora del lenguaje audiovisual. Barcelona: Paidós.

Sapró, M. (2012). Voces del Infierno. En T. Fraile y F. Viñuela (Eds), La música en el lenguaje audiovisual (pp. 193-206). Madrid: Arcibel,

Schönberg, A. (1974). Tratado de Armonía. Madrid: Real Musical.

Sebastián, S. (1988). Iconografía medieval. Donostia: Etor.

Sedeño, A. (2010). Videojuegos como dispositivos culturales: las competencias espaciales en educación. Comunicar: Revista Cientifica de Comunicación y Educación 17 (34), Huelva, mayo, pp. 183-189.

Sloboda, J. (1999). Music, where cognition and emotion meet. Psychologist 32, Estados Unidos, octubre, pp. 450-455

Sonnenschein, D. (2001). Sound design: The expressive power of music, voice, and sound effects in cinema. Studio City: Michael Wiese Productions.

Trainor, L. J., Tsang, C. D. y Cheung, V. H. W. (2002). Preference for Sensory Consonance in 2 and 4 Month Old Infants. Music Perception 20 (2), Canadá, mayo, pp. 187-194.

Vigotsky, L.S. (1972). Psicología del arte. Barcelona: Barral.

VV AA (2007). La música i el III Reich. Barcelona: Fundació Caixa de Catalunya.

Wingstedt, J., Brändström, S. y Berg, J. (2010). Narrative music, Visuals and Meaning in Films. Visual Communication 9 (2), Reino Unido, abril, pp. 193-210.

Zamacois, J. (1978). Teoría de la Música. Barcelona: Labor.

\section{Filmografía}

Amati. E. (productor) y De Martino, A. (director) (1974). El Anticristo [cinta cinematográfica]. Italia: Capitolina Produzioni.

Bernhard, H. (productor) y Donner, R. (director) (1976). La profecía [cinta cinematográfica]. EEUU: 20th Century Fox.

Blatty, W. (productor) y Friedkin, W. (director) (1973). El Exorcista [cinta cinematográfica]. EEUU: Warner Bros. Pictures.

Cooper, M. y Schoedsack, E. (productores y directores) (1933). King Kong [cinta cinematográfica]. EEUU: Radio Pictures.

Corman, G. (productor y director) (1960). La pequeña tienda de los horrores [cinta 
MHCJ Vol. 12 (1) | Año 2021 - Artículo no 10 (177) - Páginas 203 a 219 - mhjournal.org cinematográfica]. EEUU: Filmgroup.

Johnson, B., Kosove, A. y Yorkin, C. (productores) y Villeneuve, D. (director) (2017). Blade Runner 2049 [cinta cinematográfica]. EEUU: Alcon Entertainment.

Kennedy, K. y Molen, G. (productores) y Spielberg, S. (director) (1993). Jurassic Park horrores [cinta cinematográfica]. EEUU: Amblin Entertainment.

Kubrik, S (productor y director) (1968). 2001, Odisea en el espacio [cinta cinematográfica]. Reino Unido: Metro Goldwyn Mayer.

Kurtz, G y Lucas, G. (productores) y Lucas, G. (director) (1977). Star Wars [cinta cinematográfica]. EEUU: Lucasfilm.

Mooris, J. y Collins, J. (productores) y Stanton, A. (director) (2008). Wall-E [cinta cinematográfica]. EEUU: Pixar.

Moorsella, F., Cicogna, B. y Mancini, C. (productores) y Leone, S. (1968). Érase una Vez en el Oeste [cinta cinematográfica]. Italia: Finanzia San Marco.

Shaye, R. (productor) y Craven, W. (director) (1984). A Nightmare on Elm Street [cinta cinematográfica]. EEUU: New Line Cinema.

Welles, O. y Schaefer, G. (productores) y Welles, O. (director) (1941). Citizen Kane [cinta cinematográfica]. EEUU: Mercury Productions. 
MHCJ Vol. 12 (1) | Año 2021 - Artículo no 10 (177) - Páginas 203 a 219 - mhjournal.org

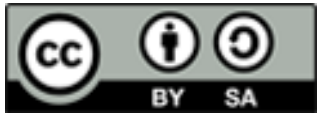

Licencia Creative Commons

Miguel Hernández Communication Journal

mhjournal.org

\section{Cómo citar este texto:}

Adrien Faure Carvallo, Diego Calderón Garrido, Josep Gustems Carnicer (2021): Lo siniestro en el audiovisual: Caracterizaciones sonoras en Miguel Hernández Communication Journal, Vol. 12 (1), pp. 203 a 219. Universidad Miguel Hernández, UMH (Elche-Alicante). DOI: https://doi.org/10.21134/mhcj.v12i.942 